susceptibility testing of Staphylococcus aureus. J Clin Microbiol 1995;33:2395-2399.

15. Association des pays de la Loire pour l'éviction des infections nosocomiales. Etude épidémiologique multicentrique sur les infections à Staphylococcus aureus résistants à la méticilline dans les hôpitaux de la région des pays de la Loire. Bull Epidemiol Hebdom 1995;27:121-122.

16. Mertens R, Jans B, Kurz X. A computerized nationwide network for nosocomial infection surveillance in Belgium. Infect Control Hosp Epidemiol 1994;15:171-179.

17. Boyce JM. Should we vigorously try to contain and control methicillin-resistant Staphylococcus aureus? Infect Control Hosp
Epidemiol 1991:12:46-54.

18. Casewell MW, Hill RLR. Minimal dose requirements for nasal mupirocin and its role in the control of epidemic MRSA.J Hosp Infect 1991;19:35-40.

19. Cookson BD. Mupirocin resistance in staphylococci. $J$ Antimicrob Agents Chemother 1990;25:497-501.

20. Layton MC, Patterson JE. Mupirocin resistance among consecutive isolates of oxacillin-resistant and borderline oxacillinresistant Staphylococcus aureus at a University Hospital. J Clin Microbiol 1994;38:1664-1667.

\title{
Risk Factors for HIV Fetal Transmission
}

\section{Gina Pugliese, RN, MS; Martin S. Favero, PhD Medical News Editors}

A substantial portion of perinatally acquired HIV-1 infections occur at or near delivery, suggesting that obstetrical factors may have an important influence on transmission. Dr. Sheldon Landesman of the State University of New York Health Science Center at Brooklyn and colleagues recently studied the relationship of such factors to perinatal transmission of HIV-1. 1 The Women and Infants Transmission Study is a prospective, observational study of HIV-1 infected women at institutions in New York City, Chicago, Massachusetts, and San Juan, Puerto Rico, who were enrolled during pregnancy and followed with their infants for 3 years after delivery. This study followed 525 women who delivered live infants whose HIV status was known. Among the mothers with mem- branes that ruptured more than 4 hours before delivery, the rate of transmission of HIV-1 to the infants was $25 \%$, as compared with $14 \%$ among mothers with membranes that ruptured 4 hours or less before delivery. In a multivariate analysis, the presence of ruptured membranes for more than 4 hours nearly doubled the risk of transmission regardless of the mode of delivery. Other maternal factors independently associated with transmission were illicit drug use during pregnancy, low antenatal CD4+ lymphocyte count, and birth weight $<2,500$ grams.

The authors concluded that the risk of HIV transmission from mother to infant increases when the fetal membranes rupture more than 4 hours before delivery. Translating this information into clinical practice will be difficult, the authors note. The current care of pregnant women infected with HIV-1 includes zidovudine therapy to reduce the risk of transmission of HIV, and there is no evidence that transmission could be reduced further by combining zidovudine with shortening of the duration of ruptured membranes.

In an accompanying editorial, Dr. Daniel Landers and Dr. Richard Sweet from Magee Women's Hospital in Pittsburgh note that these data suggest that exposure to HIV in cervicovaginal secretions increases the risk of infection, but other factors also may be implicated, such as the viral load in the plasma. ${ }^{2}$

FROM: 1. Landesman $\mathrm{SH}$, Kalish LA, Burns DN, et al. Obstetrical factors and the transmission of HIV Type I from mother to child. N Engl J Med 1996;334:16171623.

2. Landers DV, Sweet RL. Reducing mother-to-infant transmission of HIV-the door remains open. N Engl J Med 1996;334:16641665. 